\title{
Evaluation of the Convection Heat Transfer Coefficient in a Thermoelectric Distillation System
}

\author{
Hayder Al-Madhhachi \\ School of Engineering \\ Cardiff University \\ Cardiff, United Kingdom \\ Al-MadhhachiHS@Cardiff.ac.uk
}

\author{
Martin Prest \\ School of Engineering \\ Cardiff University \\ Cardiff, United Kingdom \\ PrestM@cardiff.ac.uk
}

\author{
Gao Min \\ School of Engineering \\ Cardiff University \\ Cardiff, United Kingdom \\ Min@cardiff.ac.uk
}

\begin{abstract}
I. Abstract - In this paper, a thermal model has been developed for a water distillation system which uses a thermoelectric module. The thermoelectric module cools a heat exchanger and extracts the latent heat of condensation from the water vapour at the cold side, releasing heat at the hot side to supplement the water heating. It is important to take into account the temperature distribution and the heat transfer of the thermoelectric distillation system to enhance the thermal performance. The model shows that the rate of water condensation is dependent upon the cold side temperature of the thermoelectric module, vapour temperature, geometry of the heat exchanger and the convection heat transfer coefficient of the heat exchanger at the cold side. The thermal model is used to analyses the experimental data of the thermoelectric distillation system. The results shows that the local convection heat transfer coefficient is $8 \mathrm{~W} / \mathrm{m}^{2} . \mathrm{K}$. Measurements of the distilled water show that the produced water has similar quality to the tap water in terms of PH, total dissolved solids and electrical conductivity values.
\end{abstract}

Keywords- Heat transfer; water distillation technology; thermoelectric module

\section{INTRODUCTION}

Drinkable water is essential to sustain life. 3.4 million People, mostly children, die every year from water-related diseases [1]. Hence, scientists are competing to find new and reasonable ways of producing pure water from brackish/saline water. Distillation is the most commonly used method of desalination, it is a phase separation method in which saline water is heated to produce the vapour, then condensed to produce freshwater [2]. With the advantage of noiseless, flexibility and reliability as well as high performance at smallvolume applications, thermoelectric module TE is more appropriate as a potential method in heating and cooling processes [3]. Thermoelectric modules can pump heat from one side to another when operated in Peltier mode. The mode has been used in many applications and systems [4]. The heat transfer through a condensing surface sets the condensation rate of vapour to distillate water. Convection, condensation and conduction are the modes of heat transfer from the vapour to the cold side of the thermoelectric module through the condensing surface. High condensation leads to high water production which consequently leads to high thermal performance [5]. The temperature difference between the condensing surface area and the surrounding vapour and the heat transfer coefficient by convection are vital factors to calculate the internal heat transfer.
Hence, it is essential to know the variation of this coefficient accurately. The most important and oldest relationship for convective heat transfer coefficient for an air-water system in solar stills was developed by R.V. Dunkle [6]. A.T. Shawaqfeh and M.M. Farid [7] have developed a new theory to predict heat transfer in solar distillation systems for indoor as well as in outdoor conditions. Several other researchers such as Z. Chen, X. Ge, X. Sun, L. Bar and Y.X. Miao [8] and R.S. Adhikari, A. Kumar and A. Kumar [9] have developed correlations for evaluation of internal heat transfer coefficients for indoor conditions. These correlations have constant values which cannot be used as a general expression. A.K. Tiwari and G. N. Tiwari [10] have studied the effect of a condensing cover's slope on internal heat and mass transfer in a passive solar distillation system under test conditions. In this paper, we evaluate the convection heat transfer coefficient $h_{c}$ of the internal heat transfer in the thermoelectric distillation system by developing a thermal model. This thermal model was validated using experimental results obtained under controlled conditions.

\section{SYSTEM DESCRIPTION}

A schematic diagram of the thermoelectric distillation system is shown in Fig. 1. The main function of using a thermoelectric module is to enhance the temperature difference between the evaporation water surface and the condensation metal surface for water production.

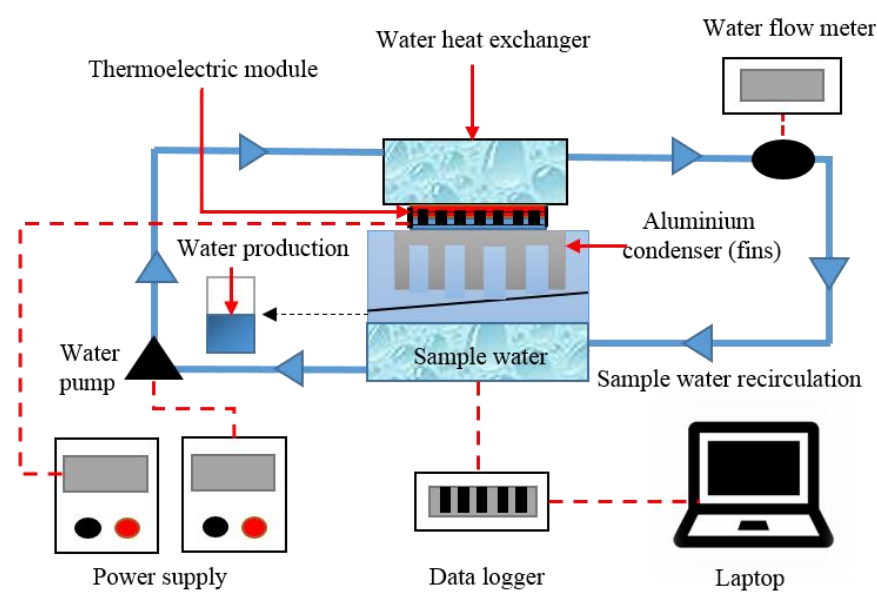

Fig. 1. Schematic diagram of the thermoelectric distillation system. 
The thermoelectric distillation system is designed and constructed as a small volume system for distillation treatment. An aluminum heat sink with fins is connected to the cold side of the thermoelectric module to condense the vapour particles and a copper heat exchanger is used to heat the feed water which passes through the hot side of thermoelectric module. Sample water flows from the top of the system over a copper heat exchanger to the bottom basin. A small pump is used to return the unevaporated water to the top of the system. In this system, there is no need for an additional heater unit for vapour production. The system consists of the thermoelectric distillation unit with two power supplies, small water pump, water flow meter and data logger connected to a laptop PC.

\section{THERMAL MODEL}

Condensation occurs when the temperature of the vapour is decreased below its saturation temperature. Practically, the process results from contact between the vapour and a cooling surface. Latent energy of the vapour is released, heat is transferred to the surface, and the condensate is formed. The water condensation rate can be determined from the relation

$$
\dot{m}=\frac{Q}{H}
$$

Where $Q$ is the transferred heat in (W) due to the condensation process and $H$ is the latent energy in $(\mathrm{kJ} / \mathrm{kg})$ due to phase - change phenomena. Latent energy of condensation can be evaluated by using STEAM TABLES OF WATER for the film water temperature $T_{f}$ [11]. The film water temperature is assumed for the latent energy calculations to be the average temperature between vapour $T_{v}$ and condenser surface $T_{s}$ in $\left({ }^{\circ} \mathrm{C}\right)$ because the water condensation on the condenser surface is a very thin layer. Fig. 2 shows the temperature profile (from the vapour by free convection to the cold side of the thermoelectric module through the aluminium condenser by conduction) can be evaluated as the following

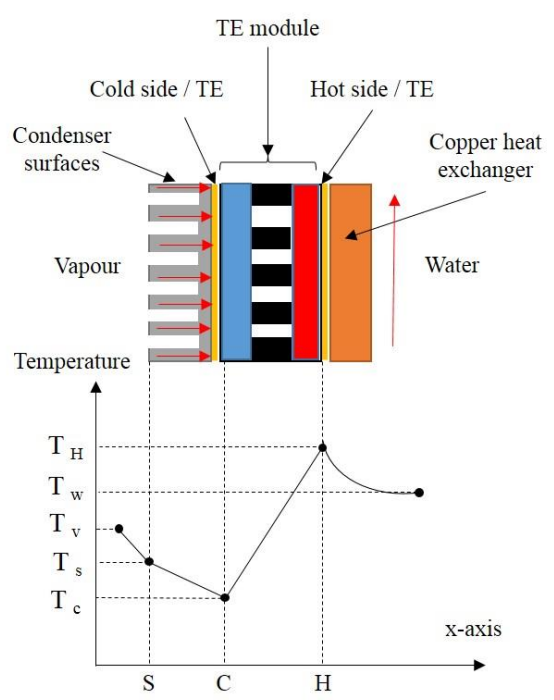

Fig. 2. Schematic of the temperature profile in a thermoelectric assisted condenser.
Useful theoretical results are obtained by making assumptions to determine the removed heat due to the condensation process: (1) The thermal properties of pure water, (2) Vapour displays ideal gas behavior and is at a uniform temperature equal to the saturation temperature, (3) Water and vapour flow are laminar, (4) Thermal conductivity of the condenser is a constant value and (5) Heat losses from the chamber are neglected. First applying a heat balance condition to a differential element at one of the fins of the aluminum condenser as shown in Fig. 3.

$$
q_{X}+d q_{\text {conv. }}=q_{x+d x}
$$

From Fourier's law [12]

$$
q_{x}=k A_{c} \frac{d T}{d x}
$$

The convection heat transfer rate expressed as

$$
d q_{\text {conv. }}=h_{c} d A_{s}\left(T(x)-T_{v}\right)
$$

The conduction heat rate at $(x+d x)$ expressed as

$q_{x+d x}=q_{x}+\frac{d q_{x}}{d x} d x=k A_{c} \frac{d T}{d x}+k \frac{d}{d x}\left(A_{c} \frac{d T}{d x}\right)$

Where $A_{c}$ is the cross section area in $\left(\mathrm{m}^{2}\right), d A_{s}$ is the surface area of the differential element in $(\mathrm{m}), h_{c}$ is the convection heat transfer coefficient in $\left(\mathrm{W} / \mathrm{m}^{2} . \mathrm{K}\right)$ and $k$ is the thermal conductivity of the aluminium in $\left(\mathrm{W} / \mathrm{m}^{2}\right)$ substituting equations. (3, 4 and 5) into (2)

$$
\frac{d^{2} T}{d x^{2}}-\frac{P h_{c}}{A_{c} k}\left(T(x)-T_{v}\right)=0
$$

To simplify the form of equation (6), transform the dependent variable by defining an excess temperature $\theta(x)$

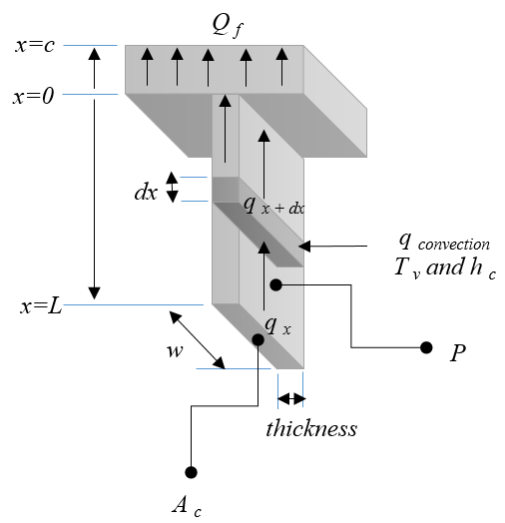

Fig. 3. Heat balance of a straight fin of uniform cross section. 


$$
\theta(x)=T(x)-T_{v}
$$

$$
\frac{d^{2} \theta}{d x^{2}}-n^{2} \theta=0
$$

$$
n^{2}=\frac{P h_{c}}{A_{c} k}
$$

Where $P$ is the fin perimeter in $(\mathrm{m}), n$ is a constant and $T(x)$ is a fin metal temperature in $\left({ }^{\circ} \mathrm{C}\right)$. Equation (8) is a linear, homogeneous, second order differential equation with constant coefficients. The general solution is

$$
\theta(x)=C_{1} e^{n x}+C_{2} e^{-n x}
$$

To evaluate the constants $C_{1}$ and $C_{2}$, it is necessary to specify two boundary conditions

At $x=c, \theta(x)=T_{c}-T_{v}$

At $x=\mathrm{L}$, At the tip of the fin, it is assumed that the rate of heat reached from the vapour by convection is equal to the rate of heat transferred by conduction

$$
h_{c} A_{c}\left(T_{L}-T_{v}\right)=k A_{c} \frac{d T}{d x}
$$

Where $T_{c}$ the cold side temperature of the thermoelectric module $\left({ }^{\circ} \mathrm{C}\right.$ ) and $L$ is the fin length (m). Solving for $C_{1}$ and $C_{2}$ after some manipulation, the temperature distribution and heat transfer rate of the fin are

$$
\begin{gathered}
\frac{T(x)-T_{v}}{T_{c}-T_{v}}=\frac{\operatorname{coshn}(L-x)+\left(\frac{h_{c}}{n k}\right) \sinh n(L-x)}{\operatorname{coshn} L+\left(\frac{h_{c}}{n k}\right) \sinh L} \\
Q_{f}=\sqrt{h_{c} P k A_{c}}\left(T_{c}-T_{v}\right) \frac{\operatorname{sinhn} L+\left(\frac{h_{c}}{n k}\right) \operatorname{coshn} L}{\operatorname{coshn} L+\left(\frac{h_{c}}{n k}\right) \operatorname{sinhn} L}
\end{gathered}
$$

Equation (14) is the total heat transfer in (W) from vapour state to the cold side thermoelectric area. It is governed by several factors, the cold side temperature of the thermoelectric module, vapour temperature, convection heat transfer coefficient and the geometry of the condenser. More challenging to define precisely is the convection heat transfer coefficient $h_{c}$. Hence, $Q_{f}$ was calculated according to the experimental temperatures and geometry whilst $h_{c}$ was fitted to the experimental results.

\section{EXPERIMENTAL SETUP}

The system creates a thermal distillation process using a thermoelectric module for evaporation and condensation. Fig. 4 shows an experimental setup including the power supplies, the multi meters, the digital scale and flow meters connected to the thermoelectric distillation system. The setup is designed to accommodate one thermoelectric module $(62 \mathrm{~mm}$ x $62 \mathrm{~mm})$ sandwiched between two heat exchangers. The top heat exchanger (black) was mounted on the hot side of the thermoelectric module and the bottom one (fins) was attached to the cold side of the thermoelectric module. To evaluate the thermal performance of the thermoelectric distillation system (temperatures of the system components and water productivity), the setup was tested in laboratory conditions (initial sample water and laboratory temperatures). The experiments were carried out for 60 minutes and the basin was filled with $300 \mathrm{~mL}$ of sea water with constant water flow rate 0.2 $\mathrm{L} / \mathrm{min}$. During the experiments, temperatures of local laboratory, water in the basin, vapour, condenser surface and hot / cold sides of the thermoelectric module were measured and recorded using a data logger (TC-08). The accumulated water through the condensation process and the total energy consumed by the system were measured manually.

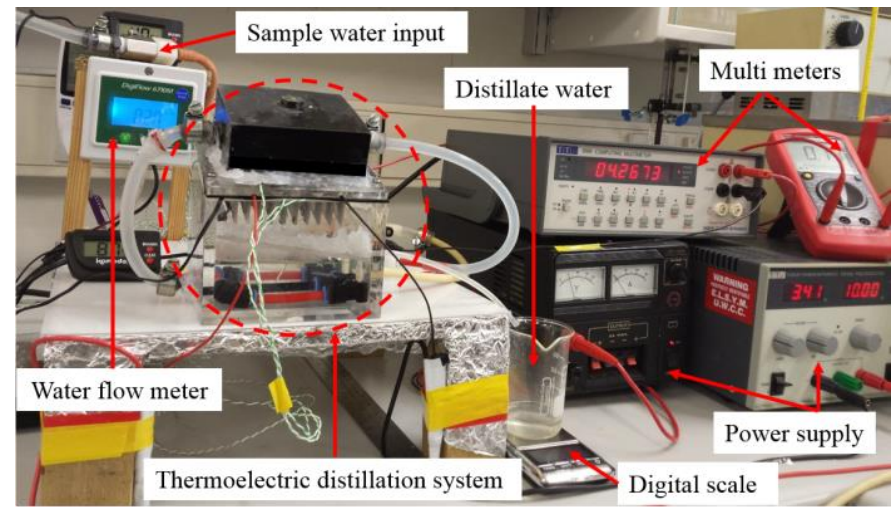

Fig. 4. The experimental setup.

\section{RESULTS AND DISCUSSIONS}

Fig. 5 shows the measured temperature variation of the system components: sample water, vapour, condenser surface, ambient and the hot / cold side of the thermoelectric module during one hour thermoelectric and water pump operation. For high condensation, the convection heat transfer between the vapour and the cooling surface should be high which leads to increased water production. There is a significant variation with the initial time, the minimum cold side temperature was -10.36 ${ }^{\circ} \mathrm{C}$ with $1.7^{\circ} \mathrm{C}$ minimum condenser surface temperature, while the temperatures of the hot side of TE module and water was increased gradually with the same trend. The experimental data were used to calculate the amount of heat transmitted and the water condensation (Equations 14 and 1). The convection heat transfer coefficient is proportional to the difference between the condenser surface and the vapour temperatures and directly proportional to the rate of heat transfer. 
The amount of water condensation at a specific time (from 0 to $60 \mathrm{~min}$ ) was calculated at different values of the convection heat transfer coefficient of gases for free convection $(6-10$ $\mathrm{W} / \mathrm{m}^{2} . \mathrm{K}$ ) [12] as shown in Fig. 6. Experimentally, the average amount of water produced was $28.5 \mathrm{~mL}$ over a period of onehour system operation. The total electrical energy (thermoelectric and water pump operation) required for the water production was $35.5 \mathrm{~W}$. The total energy consumption of the system for one hour was $0.0355 \mathrm{kWh}$, which can be classified as an economic system.

\section{A. Model Validation with Experimental Data}

Fig. 7 shows the amount of water condensate collected over one hour for experimentally measured and theoretically predicted values. The theoretical model (R-squared value $=0.9929)$ reliably predicts the amount of water condensate produced $(\mathrm{R}$-squared value $=0.9906)$ by the thermoelectric distillation system at $h_{c}=8 \mathrm{~W} / \mathrm{m}^{2} . \mathrm{K}$.

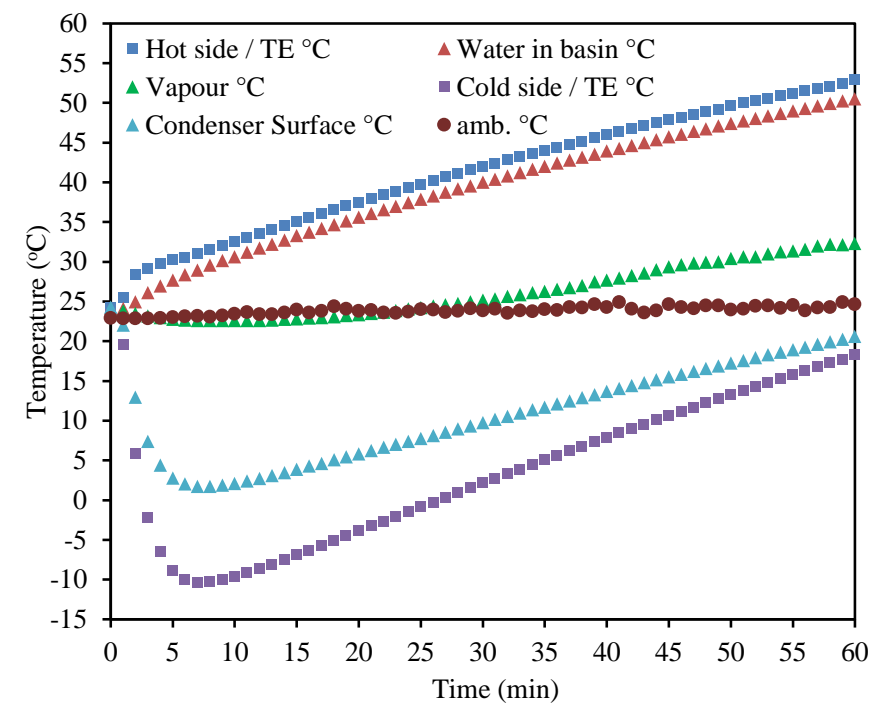

Fig. 5. The temperature variation of the system components.

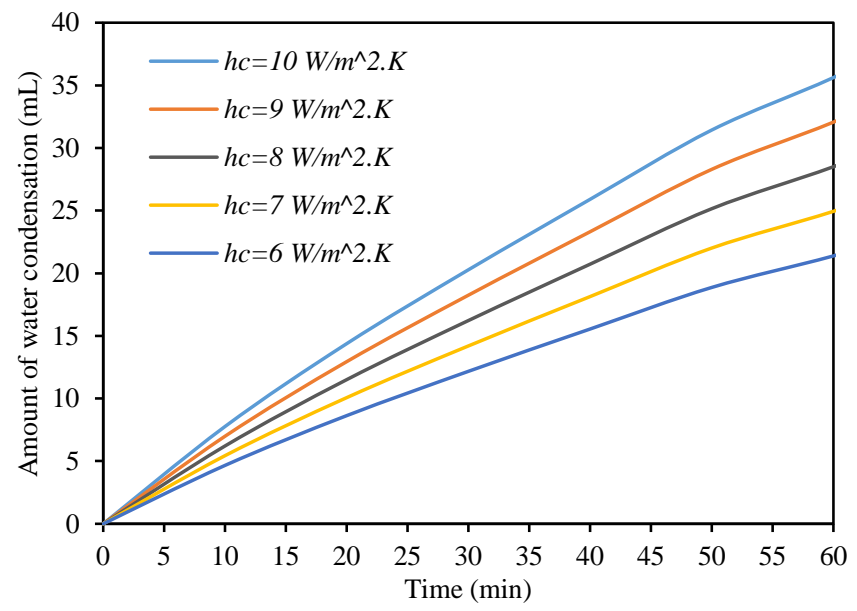

Fig. 6. The water condensation at different convective heat transfer coefficient calculated using the thermal model.

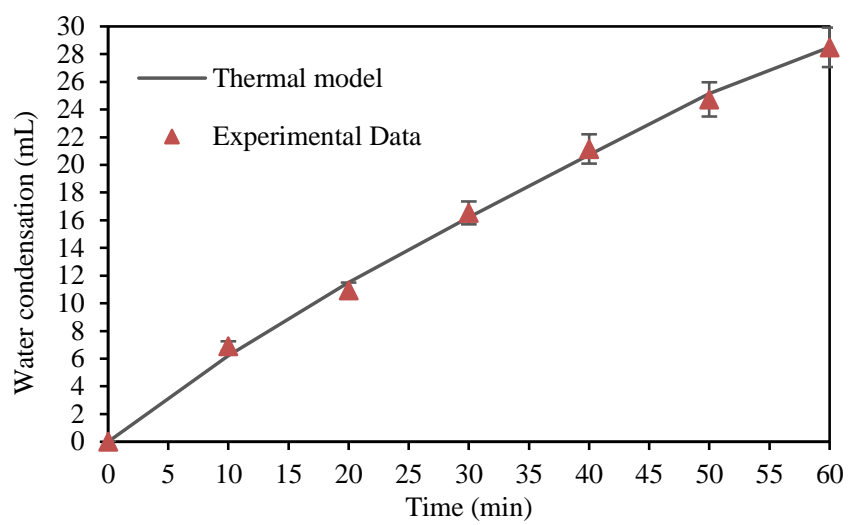

Fig. 7. The thermal model validation with the experimental water condensation at $h_{c}=8 \mathrm{~W} / \mathrm{m}^{2} . \mathrm{K}$.

\section{B. Cost of Fabricated Thermoelectric Distillation System}

Cost estimation for different components used in the present work is given in Table 1 . The cost of fabrication was about $£ 45$. The main contributors to the cost are the thermoelectric module and the water pump.

\section{Water Quality Results}

The PH (acidic / basic water level), TDS (total dissolved solids in ppm) and water conductivity $(\mu \mathrm{S} / \mathrm{cm})$ of the inlet and distilled water were measured for each day of the experiments. The results of the two last days are shown in Table 2. Before distillation process, the level of TDS and electrical conductivity in the water were high, but not drinkable. However, after distillation process, these parameters decreased significantly, which is drinkable. It is usually in the range of 6.5 to 8 so the distilled water is also acceptable $\mathrm{PH}$.

\section{TABLE I. COST OF FABRICATED TE DISTILLATION SYSTEM}

\begin{tabular}{|c|c|}
\hline Component & Cost in $£$ \\
\hline Plexiglas chamber $(1$ sheet $+8 \mathrm{~mm})$ & 1.5 \\
\hline Thermoelectric module $(62 \mathrm{~mm} \times 62 \mathrm{~mm})$ & 19.4 \\
\hline Water pump (diaphragm $1.2 \mathrm{MPa})$ & 9.69 \\
\hline Heat exchanger (copper + aluminum) & 10 \\
\hline Thermal silicon paste & 1.5 \\
\hline Plastic pipes and fittings & 2.53 \\
\hline Total cost & 44.62 \\
\hline
\end{tabular}

TABLE II. PH, TDS AND CONDUCTIVITY OF THE EXPERIMENTS

\begin{tabular}{|c|c|c|c|}
\hline \multirow{2}{*}{} & \multicolumn{3}{|c|}{ Day 1 } \\
\cline { 2 - 4 } & PH & TDS (ppm) & Conductivity $(\boldsymbol{\mu}$ S/cm) \\
\hline Inlet water & 7.8 & 863 & 1412 \\
\hline Distilled water & 7.35 & 156 & 319 \\
\hline \multirow{3}{*}{} & \multicolumn{3}{|c|}{ Day 2 } \\
\cline { 2 - 4 } & PH & TDS (ppm) & Conductivity $(\boldsymbol{\mu}$ S/cm) \\
\hline Inlet water & 7.79 & 858 & 1398 \\
\hline Distilled water & 7.34 & 151 & 312 \\
\hline
\end{tabular}




\section{CONCLUSIONS}

A thermal model has been developed for a water distillation system which uses a thermoelectric module. The following conclusions can be made on the basis of the present study:

- For thermoelectric distillation system, the thermal model can be used for determination of the key parameters that control the condensation process and the system thermal performance.

- The model shows that the rate of water condensation is dependent upon the convection heat transfer coefficient of the heat exchanger at the cold side.

- The value of the convection heat transfer coefficient for the thermoelectric distillation system is $8 \mathrm{~W} / \mathrm{m}^{2} . \mathrm{K}$.

- A significantly low total energy consumption 0.0355 $\mathrm{kWh}$ would allow the thermoelectric distillation system to be powered by solar cells.

- Measurements of the distilled water show that the produced water has similar quality to the tap water in terms of $\mathrm{PH}$, total dissolved solids and electrical conductivity values.

\section{ACKNOWLEDGMENT}

Hayder Al-Madhhachi wishes to acknowledge financial support from the Ministry of Higher Education and Scientific Research, University of Kufa, Iraq. Also, EPSRC (UK) is acknowledged for partial support of the project under UKTEG (EP/K029142/1).

\section{REFERENCES}

[1] World Health Organization. Guidelines for drinking-water quality: recommendations, 3rd ed., vol. 1, Geneva: WHO, 2004.

[2] V. G. Gude, N. Nirmalakhandan and S. Deng, "Renewable and sustainable approaches for desalination," Renewable and Sustainable Energy Reviews, vol. 14, pp. 2641-2654, December 2010.

[3] H. Wei, G. Zhang, X. Zhang, J. Ji, G. Li, and X. Zhao, "Recent development and application of thermoelectric generator and cooler," Applied Energy, vol. 143, pp. 1-25, April 2015.

[4] A. Gupta, S. Chand, N.K. Patel, A. Soni, "A Review on Thermoelectric Cooler," International Journal for Innovative Research in Science and Technology, vol. 2, pp. 674-9, May 2016.

[5] P.K. Abdenacer and S. Nafila. "Impact of temperature difference (watersolar collector) on solar-still global efficiency," Desalination, Kingdom of Bahrain, vol. 209, pp. 298-305, April 2007 [Digests 9th Arab International Conference on Solar Energy. Kingdom of Bahrain, 2007].

[6] R.V. Dunkle, "Solar water distillation, the roof type solar still and a multi effect diffusion still," International Developments in Heat Transfer, ASME, United States, vol. V, pp. 895, January 1961.

[7] A.T. Shawaqfeh and M.M. Farid, "New development in the theory of heat and mass transfer in solar stills," Solar Energy, vol. 55, pp. 527-535, December 1995 .

[8] Z. Chen, X. Ge, X. Sun, L. Bar and Y.X. Miao, "Natural convection heat transfer across air layers at various angles of inclination," Engineering Thermophysics, vol. 26, pp. 211-220, 1984.

[9] R.S. Adhikari, A.Kumar and A. Kumar, "Estimation of mass transfer rates in solar stills,” Intern. J. Energy Res., vol. 14, pp. 737-744, May 1990.

[10] A.K. Tiwari and G. N. Tiwari, "Effect of the condensing cover's slope on internal heat and mass transfer in distillation: an indoor simulation," Desalination, vol. 180, pp. 73-88, August 2005.

[11] Keenan, J. Henry and J.H. Keenan, Steam tables: thermodynamic properties of water, including vapour, liquid, and solid phases. (English units). New York: John Wiley, 1969.

[12] T.L. Bergman, F.P. Incropera, D.P. Dewitt, and A.S. Lavine, Fundamentals of heat and mass transfer. John Wiley \& Sons, April 2011. 